\title{
Assessment of Plant Diversity of a Seasonal Tropical Wetland Forest Ecosystem in Bangladesh
}

\author{
SAJAL SAHA ${ }^{1}$, MUHA ABDULLAH AL PAVEL $*^{2} \&$ MOHAMMAD BELAL UDDIN $^{1}$ \\ ${ }^{1}$ Department of Forestry and Environment Science, School of Agriculture and Mineral Sciences, \\ Shahjalal University of Science and Technology, Sylhet 3114, Bangladesh; ${ }^{2}$ Institute of Social Science, \\ University of Lisbon, Av. Professor Aníbal de Bettencourt, 9, 1600-189 Lisbon, Portugal \\ *Corresponding author: pavel.sust@gmail.com
}

\begin{abstract}
The quantitative analysis of plant diversity was explored on a seasonal tropical wetland forest ecosystem at Ratargul Swamp Forest. The simple random sampling protocol was adopted, and 30 plots (10 m $\times 10 \mathrm{~m})$ each with one subplot $(2 \mathrm{~m} \times 2 \mathrm{~m})$ was investigated for the vegetation survey. The study found about 539 individuals of 48 species belonging to 36 families. Poaceae was the dominant among all family. The upper (trees with all size) and lower (shrubs, herbs, climbers, grasses) stratum was dominated by Pongamia pinnata and Clinogyne dicotoma, respectively. The taxonomic diversity was moderate in both lower and upper strata. The value of floristic quality index was calculated at 19.92 , which represents moderate vegetative quality. The outcome also revealed the disturbances which influenced the plant community, mostly due to branch cutting by human $(<30 \%)$. The findings will be useful for the conservation and scientific management of biodiversity as a hotspot in seasonal tropical wetland forest system.
\end{abstract}

Keywords: Biodiversity, conservatism, disturbance, hotspot, wetland

Copyright: This is an open access article distributed under the terms of the CC-BY-NC-SA (Creative Commons Attribution-NonCommercial-ShareAlike 4.0 International License) which permits unrestricted use, distribution, and reproduction in any medium, for non-commercial purposes, provided the original work of the author(s) is properly cited

\section{INTRODUCTION}

Tropical forests are the most species rich ecosystem in the world. Tropical swamp forests are more complex forest ecosystem with rich biodiversity that are associated with abundant trees and high shrubs (Keddy, 2010; Vijayakumar \& Vasudeva, 2011; Islam et al., 2017). Bangladesh, located in the delta of one of the world's major river systems, is a land of vast water and wetlands. More than two thirds of the landmasses of this country have been classified as wetlands according to the definition of the Ramsar Convention (Alam et al., 2012).

The most important freshwater wetlands occur in the Hoar Basin apart from the GangesBrahmaputra delta, which is low lying plains in eastern Mymensingh and western Sylhet divisions, in the north eastern part of the country (Alam et al., 2012). Wetland ecosystems are of great importance to Bangladesh due to its extent and its economic and ecological roles in sustaining life and livelihoods options in the country. Ratargul Swamp Forest (RSF) is one of the remaining fresh water swamp forests in
Bangladesh. This falls under the category of fresh water wet evergreen forest (Sharmin et al., 2016). These swamp forests have a wide range of biological, hydrological, economic social, cultural and aesthetic values (Vijayakumar \& Vasudeva, 2011). It is one of the most important habitats for a large variety of flora and fauna of local, national and regional significance. However, rapidly increasing land development and extensive agricultural operations pose significant challenges to the survivability and sustainability of this wetland ecosystems. Remaining natural areas display varying degrees of diversity and quality of forest health because of habitat alterations. Moreover, many of the native plant species have been reduced or eliminated from vast areas where they formerly occurred. Besides, there is little quantitative information available on the composition and structure of flora in RSF.

So, it has become inevitable to assess qualitative and quantitative vegetation study at RSF to form baseline information for implementing proper management programme. The study was undertaken to determine the 
species composition, floristic quality of the major plant communities of RSF.

\section{MATERIALS AND METHODS}

\section{Study site}

Ratargul Swamp Forest (RSF) lies between $25^{\circ} 00.025^{\prime} \mathrm{N}$ latitude and $91^{\circ} 58.180^{\prime} \mathrm{E}$ longitude in Gowainghat upazilla (Sub-district), Sylhet (district), Bangladesh (Figure 1; GOB, 2010). Administratively, it is under the Sylhet forest division and located nearly northeast of Sylhet, one of divisional city of Bangladesh. The total area of RSF is about 204 ha (Hossain et al., 2016). The climate usually receives heavy rainfall. Total annual average rainfall is about $4162 \mathrm{~mm}$. The temperature varies with average maximum $32^{\circ} \mathrm{C}$ in May-October to minimum $12^{\circ} \mathrm{C}$ in January. The relative humidity is about $74 \%$ in December to $90 \%$ in July-August. Geographically, the area is plain or low land, but the rest of the land is surrounded by water (Choudhury et al., 2004). The soils are gray, heavy, silt-clay loam with clays that predominates. The soil under the vegetation is mostly clayey loam to clayey in texture. The soils become dry and heavy cracks after rainy season. The soil of the forest can be categorized as sandy to sandy-loam (Debashish et al., 2013).

\section{Sampling protocol}

The simple random sampling protocol was adopted for the vegetation survey. Thirty sample square plots of $10 \mathrm{~m} \times 10 \mathrm{~m}(0.01 \mathrm{ha})$ were used for trees $(\mathrm{dbh} \geq 5 \mathrm{~cm})$, and one square subplot of $2 \mathrm{~m} \times 2 \mathrm{~m}$ was taken within each plot to count and identify seedlings (diameter at collar region < $2.5 \mathrm{~cm}$ and height $<1 \mathrm{~m}$ ) (Pavel et al., 2016), shrubs, and herbs. The location of each plot was recorded by hand mobile GPS (GARMIN, 12 channel) and area delineated through linear measuring tape. A comprehensive species and undergrowth survey was conducted. All species composition was divided into two strata. One was upper stratum, and another was lower stratum. Trees with all sizes were considered as upper stratum whereas shrubs, herbs, climbers and grasses together were considered as lower stratum. The name and presence number of

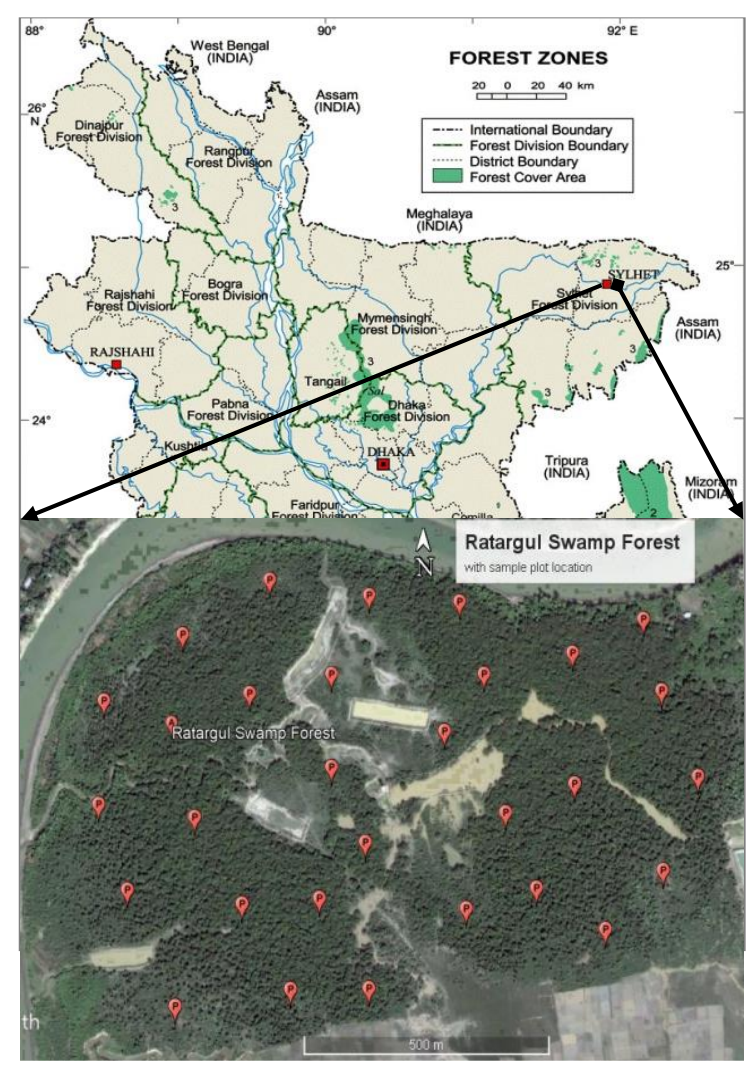

Figure 1. Location map of Ratargul Swamp Forest (RSF) (GOB, 2010).

disturbances in each plot were recorded by visual estimation. Then, percentage value for each of disturbance for all sample plot was made.

The crude density refers to the number of individuals of a particular species per unit area. The proportion of a species to that of stand is referred to as relative density. Additionally, frequency refers to the degree of dispersion in terms of percentage occurrence. The dispersion of species in relation to that of all the species is termed as relative frequency of a species. Again, the estimated number of individuals of a species per unit area is referred to as abundance. The parameters commonly were used to characterize the structure of plant community by the following formula (Shukla \& Chandel, 2000):

\section{Density of a species}

$=\frac{\text { Total number of individuals of a species in all the sample plots }}{}$ Total number of sample plots studied

\section{Relative density of a species}

$$
=\frac{\text { Total number of individuals of a species }}{\text { Total number of individuals of all species }} \times 100
$$


Frequency of a species

$=\frac{\text { Total number of quadrates in which the species occur }}{\text { Total number of quadrates studied }} \times 100$

Relative frequency of a species

$=\frac{\text { Frequency of the species }}{\text { Sum of the frequencies for all species }} \times 100$

Abundance of a species

Total number of individuals of a species in all quadrates

$=\frac{\text { Total number of quadrates of which the species occured }}{100}$

Diversity Index is a quantitative measure that reflects how many different types there are in a dataset and simultaneously considers how evenly they are distributed (Okpiliya, 2012). The Shanon-Wiener index for floristic diversity is used to measure the density and relative density of RSF (Rahman et al., 2013). Species richness index and species evenness index were also calculated using Margalef's formula (1958):

Shannon-Wiener index $\left(\mathrm{H}^{\prime}\right)=-\sum P i \ln p i$

Species diversity index $(\mathrm{SDI})=\mathrm{S} / \mathrm{N}$

Species richness index $\quad(\mathrm{R})=(\mathrm{S}-1) / \mathrm{ln} \mathrm{N}$

Species evenness index $\quad(E)=H / \ln S$

Simpson index

(D) $=\sum_{i=1}^{s} \boldsymbol{P} \boldsymbol{i}^{2}$

Where, $\mathrm{S}$ is the number of species; $i$ is the number of individuals of each species; $P i$ is the number of individuals of one species divided by total number of individuals in the samples; $\mathrm{N}$ is the total number of individuals in the sample.

Floristic quality assessment (FQA) is a promising tool based on the concept of species conservatism. It is an indication of native vegetative quality for an area: generally, low vegetative quality (1-19); high vegetative quality (20-25) and "natural area" quality $(>35)$ (Swink \& Wilhelm, 1994). The coefficient of conservatism (CC) were consider ranked based on some criteria (Table S3). The floristic quality was calculated by the following formulas (Andreas et al., 2004; Mortellaro et al., 2012):

$$
\begin{aligned}
& \text { Mean CC }=\sum_{i=1}^{n} C C i / \mathrm{N} \\
& \text { Floristic quality index }(\mathrm{FQI})=\left(\sum_{i=1}^{n} C C i / \mathrm{N}\right) \sqrt{\mathrm{N}} \\
& \text { FQI native }=\left(\sum_{i=1}^{n} C C i / \mathrm{Nn}\right) \sqrt{\mathrm{Nn}} \\
& \text { Adjusted FQI }=\frac{\left(\sum_{i=1}^{n} C C i / \mathrm{N}\right)}{10} \frac{\sqrt{\mathrm{Nn}}}{\sqrt{\mathrm{N}}}(100)
\end{aligned}
$$

Where, $\mathrm{N}$ is the number of species; $\mathrm{N}_{\mathrm{n}}$ is the number of native species; $C C_{i}$ is coefficient of conservatism assigned to each species. The SPSS 20 and MS Excel 2007 were used to conduct the statistical analysis.

\section{RESULTS}

\section{Species Composition and Abundance}

The study revealed a total of 48 plant species, and among them trees (19), shrubs (3), herbs (14), climbers (7) and grasses (5) in RSF (Table S1; Table S2). The trees were highest (40\%), followed by herbs (29\%), climbers (15\%), grasses (10\%) and shrubs (6\%) (Figure 2).

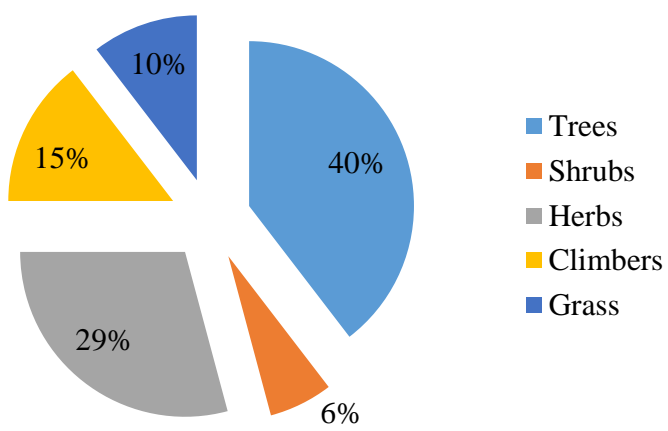

Figure 2. Percentages of plant species in RSF.

The family of Poaceae was the dominant among all. Calamus guruba was the largest in total abundance (6.42) followed by Pongamia pinnata (6) and Phragmites kakra (5). They were highly dominant and broadly dispersed in RSF. Besides, Clinogyne dicotoma, Barringtonia acutangulata, and Vetiveria zizanioide were abundance at 4.88, 4.75 and 4.67, respectively; while these can be termed as co-dominant species and less dispersed. Artocarpus lacucha and Terminalia arjuna were the lowest abundance species (Table 1). A total of 19 species were found in the upper stratum. The highest number of individuals found of Pongamia pinnata (40\%) followed by Barringtonia acutangulata (28\%) and Syzygium formosanum (11\%). A total of 268 number of tree species has density of 8.91 (Table 1). Besides, 29 species were found in the lower stratum. The highest number of individuals were Clinogyne dicotoma (47\%) followed by Calamus guruba (17\%), Vetiveria zizanioides (10\%) (Table 2). 
Table 1. Quantitative structure of upper stratum in Ratargul Swamp Forest.

\begin{tabular}{llccccccc}
\hline Scientific Name & Family & $\mathrm{N}$ & $\%$ & $\mathrm{~F}$ & $\mathrm{RF}$ & $\mathrm{D}$ & $\mathrm{RD}$ & $\mathrm{A}$ \\
\hline Pongamia pinnata & Fabaceae & 108 & 40 & 60 & 24.32 & 3.60 & 38.57 & 6.00 \\
Barringtonia acutangulata & Lythraceae & 76 & 28 & 53.33 & 21.62 & 2.53 & 27.14 & 4.75 \\
Syzygium formosanum & Myrtaceae & 30 & 11 & 33.33 & 13.51 & 1.00 & 10.71 & 3.00 \\
Crataeva nurvala & Capparidaceae & 28 & 11 & 26.67 & 10.81 & 0.93 & 10.00 & 3.50 \\
Trewia nudiflora & Euphorbiaceae & 10 & 4 & 10.00 & 4.05 & 0.33 & 3.57 & 3.33 \\
Lagerstroemia speciosa & Lythraceae & 6 & 2 & 10.00 & 4.05 & 0.20 & 2.14 & 2.00 \\
Anthocephalus chinensis & Rubiaceae & 4 & 2 & 6.67 & 2.70 & 0.13 & 1.42 & 2.00 \\
Ficus Benghalensis & Moraceae & 4 & 2 & 6.67 & 2.70 & 0.13 & 1.42 & 2.00 \\
Terminalia arjuna & Compretaceae & 1 & 0 & 3.33 & 1.35 & 0.03 & 0.35 & 1.00 \\
Artocarpus lacucha & Moraceae & 1 & 0 & 3.33 & 1.35 & 0.03 & 0.35 & 1.00 \\
\hline Total & & 268 & & & & 8.91 & & \\
\hline Note: & & & & & & &
\end{tabular}

Note: number-N; frequency-F; relative frequency-RF; density-D; relative density-RD; abundance-A

Table 2. Quantitative structure of lower stratum in Ratargul Swamp Forest.

\begin{tabular}{llccccccc}
\hline Scientific Name & Family & $\mathrm{N}$ & $\%$ & $\mathrm{~F}$ & $\mathrm{RF}$ & $\mathrm{D}$ & $\mathrm{RD}$ & $\mathrm{A}$ \\
\hline Clinogyne dicotoma & Marantaceae & 127 & 47 & 86.67 & 21.67 & 4.23 & 31.75 & 4.88 \\
Calamus guruba & Arecaceae & 45 & 17 & 23.33 & 5.83 & 1.5 & 11.25 & 6.43 \\
Vetiveria zizanioides & Poaceae & 28 & 10 & 20 & 5 & 0.93 & 7 & 4.67 \\
Eupatorium odoratum & Compositae & 20 & 7 & 26.67 & 6.67 & 0.67 & 5 & 2.5 \\
Asparagus racemosus & Liliaceae & 18 & 7 & 20 & 5 & 0.6 & 4.5 & 3 \\
Thelypteris palustris & Thelypteridaceae & 13 & 5 & 16.67 & 4.17 & 0.43 & 3.25 & 2.6 \\
Sccharum spontanium & Poaceae & 8 & 3 & 6.67 & 1.66 & 0.27 & 2 & 4 \\
Phragmites kakra & Poaceae & 5 & 2 & 3.33 & 0.83 & 0.17 & 1.25 & 5 \\
Bambusa vulgaris & Poaceae & 4 & 1 & 10 & 2.5 & 0.13 & 1 & 1.33 \\
Salvadora persica & Poaceae & 3 & 1 & 3.33 & 0.83 & 0.1 & 0.75 & 3 \\
\hline Total & & 271 & & & & 9.03 & & \\
\hline Note: & & & & & & & \\
\end{tabular}

Note: number-N; frequency-F; relative frequency-RF; density-D; relative density-RD; abundance-A 
A total of 271 individuals have density of 9.03 (Table 2). The result of most different indices in upper stratum was less than lower stratum, while Simpson index was higher in upper stratum than lower stratum. The species diversity index was less in lower stratum (0.065) than upper stratum (0.068). In addition, the value of Shanon-Weiner index was 1.8 in upper stratum and 2.5 in lower stratum (Table 3 ).

Table 3. Different diversity index for upper stratum and lower stratum in Ratargul Swamp Forest.

\begin{tabular}{cccccc}
\hline \multirow{2}{*}{ Species } & \multicolumn{5}{c}{ Floristic diversity index } \\
\cline { 2 - 6 } & $\mathrm{H}^{\prime}$ & $\mathrm{D}$ & $\mathrm{SDI}$ & $\mathrm{R}$ & $\mathrm{E}$ \\
\hline Upper stratum & 1.8 & 0.246 & 0.068 & 3.19 & 0.604 \\
& & & & & \\
Lower stratum & 2.5 & 0.139 & 0.065 & 4.17 & 0.763 \\
\hline
\end{tabular}

Note: Shannon-Wiener index-H'; Simpson index-D; Species diversity index-SDI; Species richness index-R; Species evenness index-E.

\section{Floristic Quality}

The coefficients of conservatism (CC) values were assigned to each species based on their located areas (Table S1, Table S2). The native mean of $\mathrm{CC}$ is also an indication of native vegetative quality (Figure 3). Approximately $83 \%$ of plants were assigned into the ruderal areas $(0-4)$, while $17 \%$ into obligate to natural areas (5 - 10). Among 48 species, $75 \%$ were considered native and $25 \%$ were considered non-native. The means species richness was 48 . The number of native species observed as 36 . The floristic quality was enumerated as 19.92 whereas native floristic quality as 23 . The value of adjusted floristic quality was 24.89 that should be remained in RSF (Table 4).

Table 4. Floristic quality index in Ratargul Swamp Forest.

\begin{tabular}{lc}
\hline Indices & Value \\
\hline Species richness & 48 \\
Native species richness & 36 \\
Mean (C) & 2.88 \\
Mean (C) native & 3.83 \\
Floristic quality index & 19.92 \\
Floristic quality index(native) & 23 \\
Adjusted floristic quality index & 24.89 \\
\hline Note: Coefficients of conservatism-C
\end{tabular}

\section{Disturbances}

The recorded total numbers of disturbances were 80 in all sample plots. The mean of disturbance was 2.67. Eight types of disturbance were found; among them branch cutting in wet season and grazing in dry season were mostly observed. The mostly observed disturbance was branch cutting in RSF $(\sim 29 \%)$, followed by nearly $28 \%$ in insect and disease epidemics (Figure 4).

\section{DISCUSSION}

The result represents 539 individuals that belong to 36 families and 48 species in RSF. Poaceae represented as the highest number of species among all species. The taxonomic diversity was moderate in both lower and upper strata in RSF based on the value 0 for low to 5 for high. About $75 \%$ native and $25 \%$ non-native species were identified. As consequences, native plant communities were influenced. Similarly, Mortellaro et al. (2012) assured that the nonnative plant species (approx. 15\%) altered the native plant communities. Uddin et al. (2013) also explained the same observation from managed forest in the north-eastern of Bangladesh. Furthermore, the value of floristic quality index was calculated at 19.92 representing moderate vegetative quality because this value fall between low vegetative quality (1-19) and high vegetative quality (2035 ) index. The native floristic quality index was calculated at 23 but it should be 24.89 for this study area. It is an index that measures the conservatism of the species found in the plot. Swink \& Wilhelm (1994) reported similar observation in this forest. The results revealed the disturbances influenced in plant community and the mostly observed disturbance was branch cutting by human $(<30 \%)$ in RSF (Figure 4). Both Pavel et al. (2016) and Uddin et al. (2013) reported similar observations from protected forests in Bangladesh.

As consequences, the socioeconomic changes, increasing human activities greatly change the community structure; species diversity and plant cover (Shaltout \& El-Sheikh, 2002). Therefore, forest characterization is an important factor is influencing the tree species richness in RSF. Pavel et al. (2016) reported similar study from managed forest in the north-eastern areas of Bangladesh. 


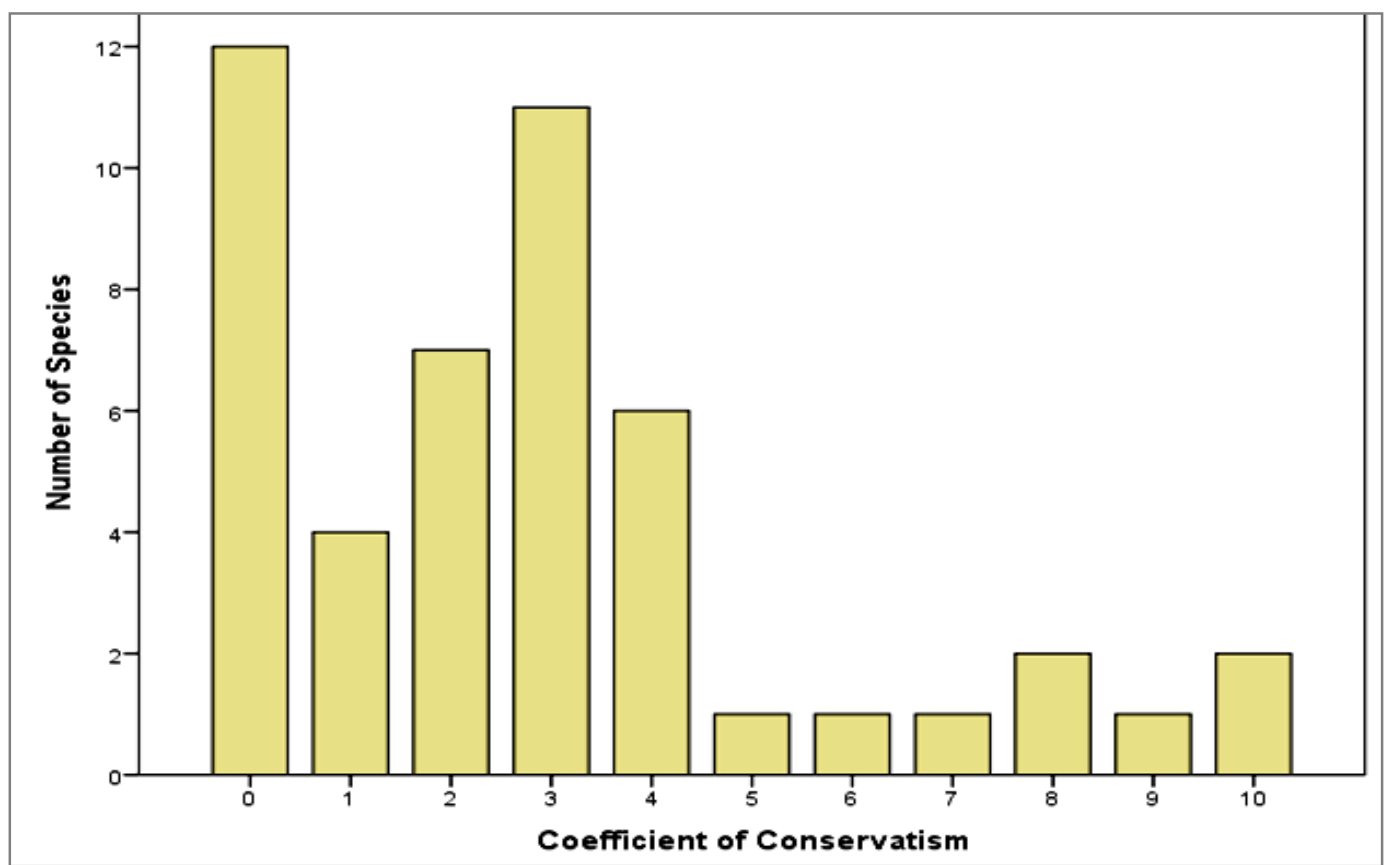

Figure 3. Distribution of coefficient of conservatism designation for graded plants in Ratargul Swamp Forest.

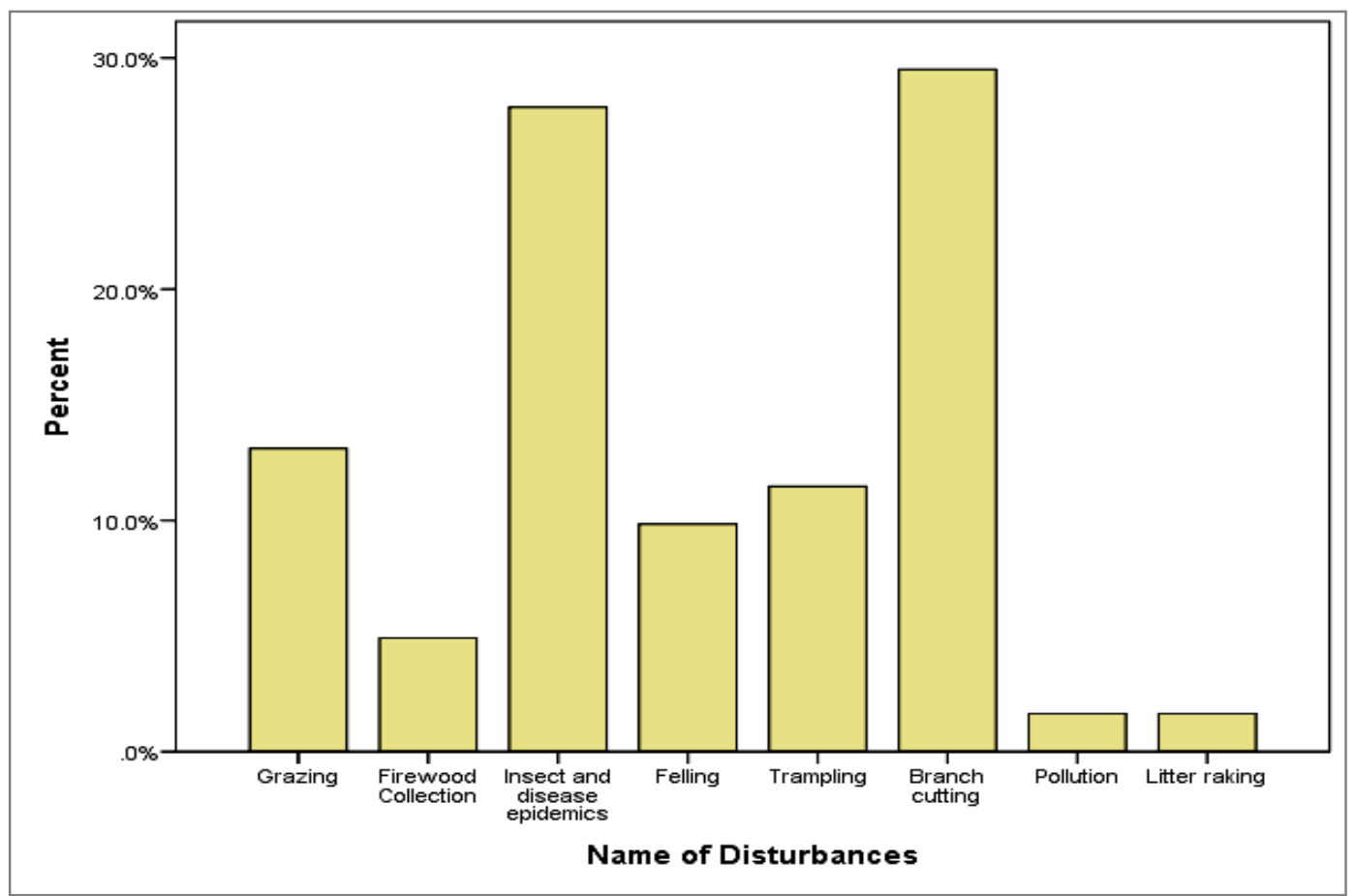

Figure 4. Distribution and percentage of disturbances in Ratargul Swamp Forest. 


\section{CONCLUSION}

The diversity of plant was moderately present in RSF. The diversity and richness will be degraded in RSF near future due to the impacts of continuous threats. The awareness urgently needs to be created among the local people about the importance of conservation of biodiversity. The alternative income generating options need to be provided and promoted to local people to conserve the biodiversity of RSF.

\section{ACKNOWLEDGEMENTS}

This study was supported by the Department of Forestry and Environment Science, Shahjalal University of Science and Technology, Bangladesh.

\section{REFERENCES}

Alam, A.B.M.S., Chowdhury, M.S.M. \& Sobhan, I. (2012). Biodiversity of Tanguar Haor: A Ramsar site of Bangladesh. Volume I: Wildlife, IUCN Bangladesh, Dhaka, Bangladesh.

Andreas, B.K., John, J.M. \& James, S.M. (2004). Floristic Quality Assessment Index (FQAI) for Vascular Plants and Mosses for the State of Ohio. Ohio Environmental Protection Agency, Division of Surface Water, Wetland Ecology Group, Columbus, Ohio.

Choudhury, J.K., Biswas, S.R., Islam, M.S., Rahman, O. \& Uddin S.N. (2004). Biodiversity of Ratargul swamp forest, Sylhet. IUCN Bangladesh.

Debashish, R., Gope, M.C. \& Alam, M.D.A. (2013). Socio-economic Impact of Tourism to the Local Residents: a case study on Ratargul Swamp Forest. Journal of Socioeconomic Research and Development, 10(5): 1557-1562.

GOB. (2010). Forest department official website. Government of people's Republic of Bangladesh, Dhaka, Bangladesh. Access at: http://www.bforest.gov.bd/land.php.
Hossain, M.Z., Khan, M.A.A.K., Kashem, M.A. \& Hoque, S. (2016). Plant community composition in relation to soil physicochemical properties of the Ratargul swamp forest, Bangladesh. Dhaka University Journal Biological Science, 25(1): 1-8.

Islam, M.A., Pavel, M.A.A., Uddin, M.B., Al Mamun, M.A., Rahman, S.A., Mathys, A.S., Indraswari, K., Bianchi, S., Harada, K. \& Sunderland, T.C.H. (2017). A tropical case study of tree diversity and productivity relationships in mixed species plantations in protected areas. International Journal of Development and Sustainability, 6(11): 1835-1847.

Keddy, P.A. (2010). Wetland Ecology: Principles and Conservation. 2nd edition. Cambridge University Press, Cambridge, UK.

Margalef, R. (1958). Information theory in ecology. International Journal of General Systematics, 3: 36-71.

Mortellaro, S., Barry, M., Gann, G., Zahina, J., Channon, S., Hilsenbeck, C., Scofield, D., Wilder, G. \& Wilhelm, G. (2012). Coefficients of conservatism values and the floristic quality index for the vascular plants of South Florida. Southeastern Naturalist, 11(3): 1-62.

Okpiliya, F. I. (2012). Ecological diversity indices: any hope for one again? Journal of Environment and Earth Science, 2(10): 4552

Pavel, M.A.A., Mukul, S.A., Uddin, M.B., Harada, K. \& Khan, M.A.A. (2016). Effects of stand characteristics on tree species richness in and around a conservation area of northeast Bangladesh. Journal of Mountain Science, 136: 1085-1095.

Rahman, S.A., Baldauf, C., Mollee, E.M., Pavel, M.A.A., Al Mamun, M.A., Toy, M.M. \& Sunderland, T. (2013). Cultivated plants in the diversified homegardens of local communities in Ganges Valley, Bangladesh. Science Journal of Agricultural Research and Management, Volume 2013, Article ID sjarm-197, 6 . 
Shaltout, K.H. \& El-Sheikh, M.A. (2002). Vegetation of the urban habitats in the Nile Delta region, Egypt. Urban Ecosystems, 6(3): 205-221.

Sharmin, M., Dey, S. \& Chowdhury, S. (2016). Relationship between Diversity and Productivity at Ratargul Fresh Water Swamp Forest in Bangladesh. Journal of Forest and Environmental Science, 32(3): 291-301.

Shukla, R.S. \& Chandel, P.S. (2000). Plant Ecology and Soil Science, 9th. Edition. S. Chand \& Company Limited, Ramnagor, New Delhi.
Swink, F. \& Wilhelm, G. (1994). Plants of the Chicago Region, $4^{\text {th }}$ Edition. Indiana Academy of Science, Indianapolis 921.

Uddin, M.B., Steinbauer, M.J., Jentsch, A, Mukul, S.A. \& Beierkuhnlein, C. (2013). Do environmental attributes, disturbances and protection regime determine the distribution of exotic plant species in Bangladesh forest ecosystems? Forest Ecology and Management, 303: 72-80.

Vijayakumar, P.K. \& Vasudeva, R. (2011). Characterization of soil properties from fresh water swamps and adjoining evergreen forest area. Karnataka Journal Agricultural Sciences, 24(4): 601-602. 